\title{
Low density lipoprotein receptor-related protein is a calreticulin coreceptor that signals focal adhesion disassembly
}

\author{
Anthony Wayne Orr, ${ }^{1}$ Claudio E Pedraza, ${ }^{1}$ Manuel Antonio Pallero, ${ }^{1}$ Carrie A. Elzie, ${ }^{1}$ Silvia Goicoechea, ${ }^{1}$ \\ Dudley K Strickland, ${ }^{2}$ and Joanne E. Murphy-Ullrich ${ }^{1}$ \\ ${ }^{1}$ Department of Pathology, Division of Molecular and Cellular Pathology and the Cell Adhesion and Matrix Research Center, \\ University of Alabama at Birmingham, Birmingham, AL 35294 \\ ${ }^{2}$ Department of Vascular Biology, Holland Laboratory, American Red Cross, Rockville, MD 20855
}

$\mathrm{T}$ hrombospondin (TSP) signals focal adhesion disassembly (the intermediate adhesive state) through interactions with cell surface calreticulin (CRT). TSP or a peptide (hep I) of the active site induces focal adhesion disassembly through binding to CRT, which activates phosphoinositide 3-kinase (PI3K) and extracellular signal-related kinase (ERK) through $\mathrm{G} \alpha_{\mathrm{i} 2}$ proteins. Because CRT is not a transmembrane protein, it is likely that CRT signals as part of a coreceptor complex. We now show that low density lipoprotein receptor-related protein (LRP) mediates focal adhesion disassembly initiated by TSP binding to CRT. LRP antagonists (antibodies, receptor-associated protein) block hep I/TSP- induced focal adhesion disassembly. LRP is necessary for TSP/hep I signaling because TSP/hep I is unable to stimulate focal adhesion disassembly or ERK or PI3K signaling in fibroblasts deficient in LRP. LRP is important in TSP-CRT signaling, as shown by the ability of hep I to stimulate association of $\mathrm{G} \alpha_{\mathrm{i} 2}$ with LRP. The isolated proteins LRP and CRT interact, and LRP and CRT are associated with hep I in molecular complexes extracted from cells. These data establish a mechanism of cell surface CRT signaling through its coreceptor, LRP, and suggest a novel function for LRP in regulating cell adhesion.

\section{Introduction}

Interactions of cells with the ECM modulate most cellular functions. Focal adhesions are specialized submembranous assemblies of both structural and signaling molecules that link the actin cytoskeleton to receptors such as integrins and syndecan-4, which recognize ECM molecules (Burridge and Chrzanowska-Wodnicka, 1996). Focal adhesions transmit both mechanical and biochemical signals that regulate cell shape and cytoskeletal organization, cell motility, cell cycle progression, gene expression, and cell survival (Yamada and Geiger, 1997; Horwitz and Werb, 1998).

\footnotetext{
Address correspondence to Joanne E. Murphy-Ullrich, Dept. of Pathology and The Cell Adhesion and Matrix Research Center, University of Alabama at Birmingham, VH 668 1530, 3rd Ave. South, Birmingham, AL 35294-0019. Tel.: (205) 934-0415. Fax: (205) 975-934. E-mail: Murphy@path.uab.edu

*Abbreviations used in this paper: $\alpha_{2} \mathrm{M}, \alpha_{2}$-macroglobulin; $\mathrm{BAE}$, bovine aortic endothelial; CRT, calreticulin; ERK, extracellular signal-related kinase; LRP, low density lipoprotein receptor-related protein; MEF, mouse embryonic fibroblast; PI3K, phosphoinositide 3 kinase; PTX, pertussis toxin; RAP, receptor-associated protein; TSP, thrombospondin. Key words: thrombospondin; G proteins; ERK; focal adhesions; cell adhesion
}

Thrombospondins (TSPs)* 1 and 2 , tenascin-C, and SPARC are matricellular proteins, which when presented to cells as soluble proteins, stimulate a transition in cell adhesion from a state of strong adhesion to one of intermediate adhesion. This is characterized by a restructuring of focal adhesion plaques with dispersal of vinculin and $\alpha$-actinin and reorganization of actin stress fibers while maintaining integrin clusters and a spread cell shape (Murphy-Ullrich, 2001). The intermediate adhesive state is regarded as the phenotype of an adaptive response that facilitates motility and potentially induces cell survival signals (Murphy-Ullrich, 2001).

TSP signals focal adhesion disassembly through interactions of a 19 amino acid sequence from its $\mathrm{NH}_{2}$-terminal heparinbinding domain with a cell surface form of calreticulin (CRT; Goicoechea et al., 2000, 2002). TSP-CRT signaling of focal adhesion disassembly is pertussis toxin (PTX)-sensitive and involves both $\mathrm{G} \alpha_{\mathrm{i} 2}$ and $\mathrm{G} \beta \gamma$ subunits (Orr et al., 2002). TSP/hep I binding to CRT stimulates a PTX-dependent activation of phosphoinositide 3-kinase (PI3K) and extracellular signal-related kinase (ERK), which are required for focal adhesion disassembly. Because CRT is not a transmembrane protein, it is likely that CRT acts in association with a coreceptor. 
The low density lipoprotein receptor-related protein (LRP), also known as CD91 or the $\alpha_{2}$-macroglobulin $\left(\alpha_{2} \mathrm{M}\right)$ receptor, is a member of a family of multi-ligand binding proteins involved in numerous biological functions (Herz and Strickland, 2001; Strickland et al., 2002). Among its ligands is the $\mathrm{NH}_{2}$-terminal heparin-binding domain of TSP; LRP mediates endocytic degradation of TSP (Godyna et al., 1995; Mikhailenko et al., 1997). There is also indirect evidence for the association of LRP with CRT. CRT competitively inhibited the association of LRP with heat shock protein gp96 (Basu et al., 2001). CRT and LRP are colocalized on the macrophage cell surface by immunohistochemistry, where they function as coreceptors for macropinocytosis of necrotic cells (Ogden et al., 2001). Although these data suggest that CRT and LRP can form bimolecular signaling complexes, there are actually no direct data to show binding of these two proteins.

Once considered primarily for its role in endocytosis, it is becoming clear that LRP and other family members associate with a number of cytoplasmic adaptor molecules and participate in signaling of multiple cellular functions (Hussain, 2001; Strickland et al., 2002). LRP is a 600-kD transmembrane protein composed of one $515-\mathrm{kD}$ heavy $(\alpha)$ subunit and one $85-\mathrm{kD}$ light $(\beta)$ subunit noncovalently attached to each other (Herz et al., 1990; Willnow et al., 1996). The light subunit has a transmembrane domain and a cytoplasmic tail that contains two NPxY sequences (Gliemann et al., 1994). These motifs are available for interactions with adaptor or scaffolding molecules, such as Shc, FE65, and Disabled-1 (Ermekova et al., 1997; Trommsdorff et al., 1998, 1999; Barnes et al., 2001). LRP is localized in caveolae, and is rapidly and transiently tyrosine phosphorylated by the PDGF receptor in a src- and PI3K-dependent manner (Boucher et al., 2002; Loukinova et al., 2002). PDGF-mediated phosphorylation of LRP's cytoplasmic domain results in increased association of the adaptor protein Shc with LRP. Expression of a chimeric protein with the LRP cytoplasmic domain increases JNK association at the plasma membrane, inhibiting JNK translocation to the nucleus and gene regulation (Lutz et al., 2002). Other LRP family members (LRP5 and LRP6) act as coreceptors with the $\mathrm{G}$ protein-coupled receptor Frizzled in the Wnt signaling pathway, suggesting a role in transcriptional regulation (Tamai et al., 2000; Wehrli et al., 2000). Finally, $\alpha_{2} \mathrm{M}$ binding to LRP on macrophages activates PI3K (Misra and Pizzo, 1998).

Here, we report that LRP acts as the coreceptor for cell surface CRT to mediate focal adhesion disassembly in response to the hep I sequence of TSP. Our results demonstrate that LRP is necessary for focal adhesion disassembly by TSP because the LRP antagonist, receptor-associated protein (RAP), or antibodies against LRP block TSP/hep I-induced focal adhesion disassembly, and LRP-deficient cells do not signal in response to TSP/hep I treatment. Furthermore, we provide the first direct evidence that LRP and CRT interact and that hep I, CRT, and LRP are complexed in cells. These results establish LRP as a signaling coreceptor for CRT and provide evidence for a novel function for LRP in regulation of cell adhesion.

\section{Results}

Anti-LRP antibodies and RAP block TSP/hep I-mediated focal adhesion disassembly

The ability of cell surface CRT to signal focal adhesion disassembly despite its lack of a transmembrane domain suggests that CRT signals through associations with a coreceptor. Recent reports showed that LRP, a known receptor for TSP, colocalizes with CRT on the surface of macrophages (Ogden et al., 2001) and that CRT can competitively block the binding of heat shock protein gp96 to LRP (CD91) on antigen-presenting cells (Binder et al., 2000). These data prompted us to ask whether LRP might act as a coreceptor for CRT to mediate TSP signaling of focal adhesion disassembly.

To test this hypothesis, we used a pAb (anti-CD91) raised against a $75-80-\mathrm{kD}$ fragment of the LRP heavy chain (extracellular domain). This antibody blocked focal adhesion disassembly by hep I (Fig. 1). Similarly, a second LRP pAb (R2629) that recognizes multiple epitopes in the ligandbinding regions of the heavy chain of LRP also blocked hep I stimulation of focal adhesion disassembly (unpublished data). These antibodies also blocked focal adhesion disassembly by TSP (unpublished data). Incubation of the cells with the antibodies alone did not affect the number of cells positive for focal adhesions, demonstrating that blockade of LRP in the absence of a TSP stimulus is not sufficient to alter focal adhesion stability.

To further investigate the role of LRP in focal adhesion disassembly, we also tested the ability of RAP to block TSPmediated focal adhesion. RAP is a chaperone for LRP (and other low density lipoprotein receptor family members) that blocks the binding of ligands to LRP (Strickland et al., 1991; Kounnas et al., 1992a; Medh et al., 1995). Pretreatment of cells with RAP blocked the ability of hep I and TSP to induce focal adhesion disassembly (Fig. 2). RAP alone

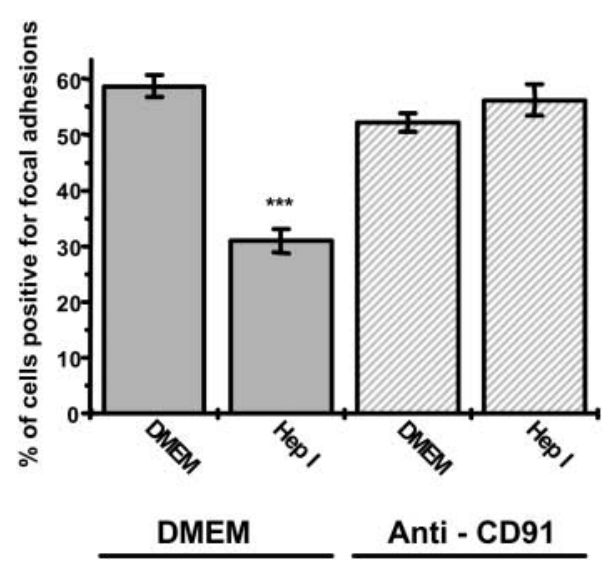

Figure 1. Anti-LRP antibody inhibits hep I-induced focal adhesion disassembly. BAE cells grown on coverslips were incubated with rabbit anti-LRP antibody (anti-CD91) for $30 \mathrm{~min}$, washed, and then incubated with $1 \mu \mathrm{M}$ hep I or DMEM (control) for $30 \mathrm{~min}$. Cells were examined by interference reflection microscopy and assayed for the percentage of cells positive for focal adhesions $\pm \operatorname{SD}(n=3)$. A minimum of 300 cells per condition were evaluated. ${ }^{* * *}, \mathrm{P}<0.001$ vs. DMEM. 


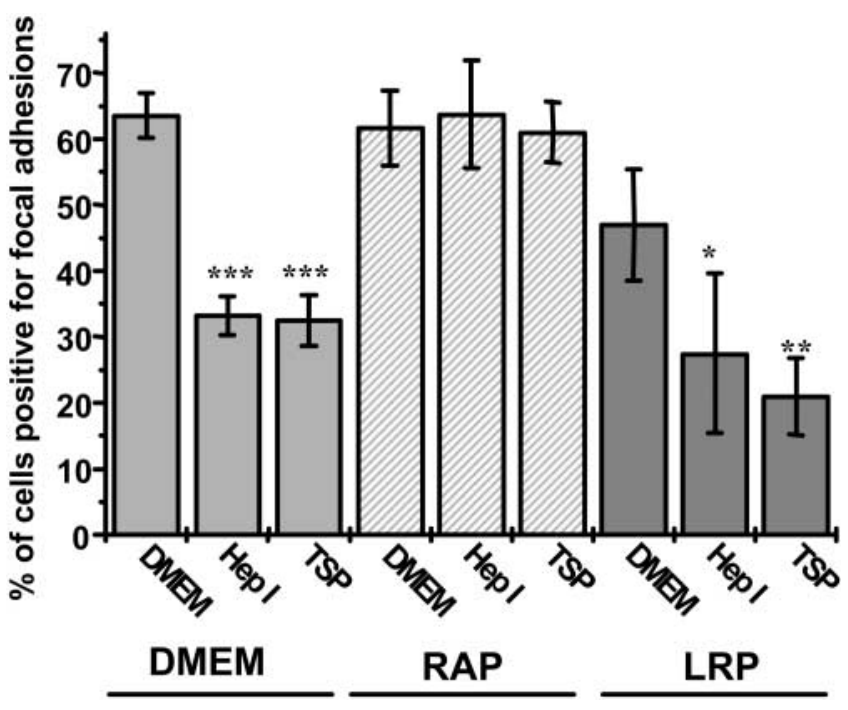

Figure 2. RAP (but not LRP) inhibits TSP/hep I-induced focal adhesion disassembly. BAE cells grown on coverslips were incubated for 30 min with $2 \mu \mathrm{M}$ RAP or DMEM (control) before addition of $100 \mathrm{nM}$ hep I or $68 \mathrm{nM}$ TSP for $30 \mathrm{~min}$. In addition, LRP at 10-fold molar excess to $100 \mathrm{nM}$ hep I or $340 \mathrm{nM}$ TSP was incubated with $10 \mathrm{nM}$ hep I or $34 \mathrm{nM}$ TSP for 30 min before addition to cells for 30 $\mathrm{min}$. Cells were fixed and examined for the number of cells positive for focal adhesions by interference reflection microscopy. Results are the mean $\pm \mathrm{SD}(n=3) .{ }^{*}, \mathrm{P}<0.05 ;{ }^{* *}, \mathrm{P}<0.01 ;{ }^{* * *}, \mathrm{P}<$ 0.001 vs. DMEM.

had no effect on the number of cells positive for focal adhesions.

The $\mathrm{NH}_{2}$ terminus of TSP binds LRP, although the exact binding site in TSP has not been identified (Godyna et al., 1995; Mikhailenko et al., 1997). Therefore, we examined whether preincubation of either hep I or TSP with LRP was able to block focal adhesion disassembly, potentially by binding to the hep I sequence and inhibiting the ability of TSP/hep I to bind CRT. LRP preincubation did not affect the ability of hep I or TSP to stimulate focal adhesion disassembly (Fig. 2). These data suggest that LRP does not bind TSP through the hep I sequence. Furthermore, we were unable to demonstrate hep I-LRP interactions in binding assays in which hep I was immobilized in microtiter wells and incubated with purified LRP (unpublished data).

\section{LRP-deficient cells do not respond to stimulation by hep I}

To further confirm whether LRP plays a role in focal adhesion disassembly, mouse embryonic fibroblasts (MEFs) genetically deficient in LRP were treated with TSP or hep I. Fibroblasts (MEF-1) wild type for LRP and fibroblasts heterozygous (PEA 10) or homozygous null (PEA 13) for LRP were used (Willnow and Herz, 1994). Cells were incubated with hep I peptide and analyzed for focal adhesions by interference reflection microscopy. Hep I was unable to stimulate focal adhesion disassembly in either the heterozygous or the homozygous LRP-null cells, although the wild-type parental line responds to TSP and hep I as previously observed for bovine aortic endothelial (BAE) cells and other MEF strains (Fig. 3). The PEA 10 cells, which are heterozygous for the
LRP gene and express $\sim 50 \%$ of wild-type levels of LRP, do not respond to hep I, suggesting that there is a critical level of LRP expression on the cells necessary to mediate focal adhesion disassembly (Fig. 3). In contrast, both PEA 10 and PEA 13 MEFs were able to respond to the active fragment of tenascin-C, suggesting that the failure to respond to TSP/ hep I is not due to a generalized defect in these cells (Murphy-Ullrich et al., 1991; Fig. 3).

\section{Binding of recombinant CRT and purified LRP}

The preceding data are supportive of a role for LRP as the signaling coreceptor for CRT. However, there is no direct evidence that LRP and CRT form a molecular complex. Therefore, we investigated binding of CRT and LRP. Binding of recombinant CRT and purified LRP was assessed by immunoprecipitation with rabbit anti-CRT antiserum, followed by immunoblotting with anti-LRP antibody to detect bound LRP. A band that migrated at the same mol wt as purified LRP was detected in samples incubated with CRT (Fig. 4). LRP was not detected in samples precipitated with nonimmune rabbit serum. Furthermore, the binding between CRT and LRP was inhibited by the LRP ligand, RAP (Fig. 4). The ability of RAP to block CRT interactions with LRP is specific for LRP because RAP does not inhibit CRT binding to TSP (unpublished data). CRT-LRP complex formation is specific in these assays, as LRP does not bind BSA (Fig. 4). These data provide direct evidence that CRT and LRP can form a molecular complex. Furthermore, the ability of RAP to block both CRT-LRP complex formation and focal adhesion disassembly by hep I strongly suggests that CRT-LRP complex formation is necessary for signaling of focal adhesion disassembly.

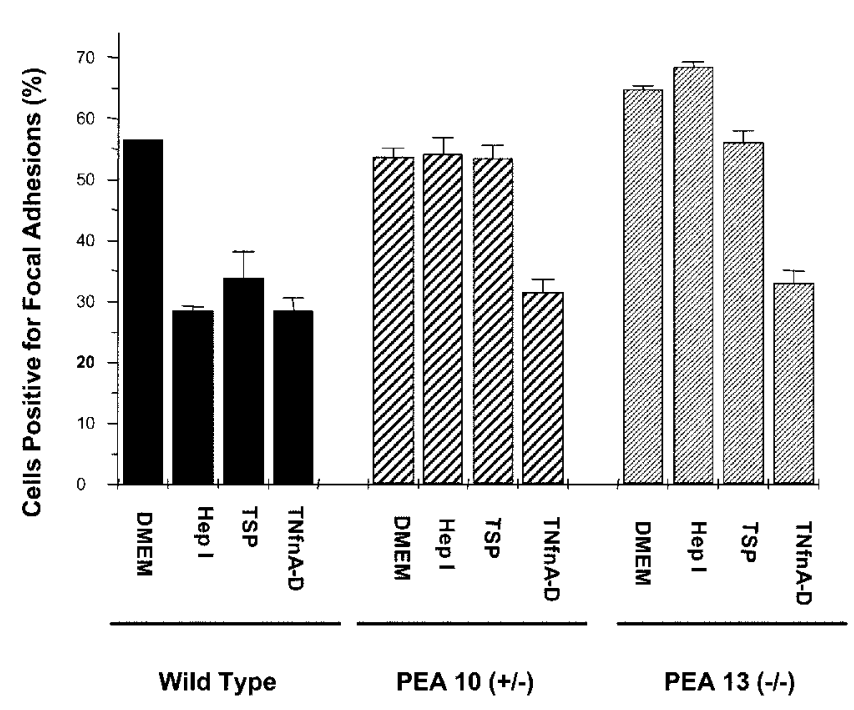

Figure 3. hep I does not induce focal adhesion disassembly. LRPdeficient wild-type (CRL-2214), PEA 10 (LRP +/-), and PEA 13 (LRP $-/-$ ) cells grown on coverslips were incubated with $1 \mu \mathrm{M}$ hep I, 68 $\mathrm{nM}$ TSP, $30 \mu \mathrm{g} / \mathrm{ml} \mathrm{TN}-\mathrm{C}$ fnllIA-D, or DMEM (untreated) for $30 \mathrm{~min}$ at $37^{\circ} \mathrm{C}$. Cells were fixed and examined for focal adhesions by interference reflection microscopy in at least 250 cells/coverslip. Results are the mean percentage of cells positive for focal adhesions \pm $\mathrm{SD}(n=3)$. 


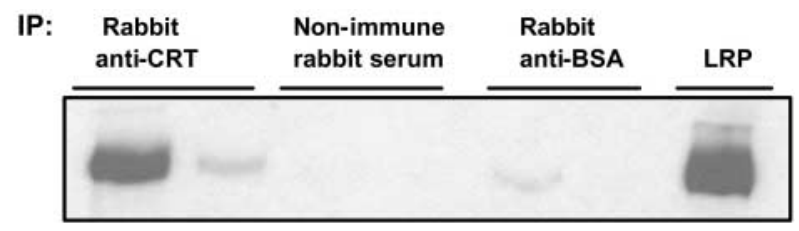

\begin{tabular}{|c|c|c|c|c|c|}
\hline LRP & + & + & + & + & + \\
\hline CRT & + & + & + & + & - \\
\hline RAP & - & + & - & + & - \\
\hline BSA & - & - & - & - & + \\
\hline
\end{tabular}

WB: anti-LRP (8G1)

Figure 4. Recombinant CRT interacts with purified LRP. $20 \mathrm{nM}$ CRT and $10 \mathrm{nM} \mathrm{LRP} \mathrm{were} \mathrm{incubated} \mathrm{together} \mathrm{in} \mathrm{the} \mathrm{presence} \mathrm{or}$ absence of $10 \mathrm{nM}$ RAP, and then complexes were immunoprecipitated with anti-CRT antiserum or nonimmune rabbit serum. Alternately, LRP was incubated with BSA, and LRP bound to BSA was immunoprecipitated with anti-BSA antibody. LRP bound to CRT or BSA was detected after electrophoresis and transfer to nitrocellulose membranes with anti-LRP antibody (8G1).

\section{CRT and LRP are associated with each other in BAE cell lysates}

To establish whether CRT and LRP form complexes in BAE cells, detergent extracts of membranes from cells treated with hep I were analyzed for the presence of CRT in antiLRP immunoprecipitates. CRT is present in anti-LRP (but not in nonimmune $\mathrm{IgG}$ ) immunoprecipitates, indicating that the two proteins are associated in cells. Treatment with hep I, but not modified hep I, enhances association of LRP and CRT (Fig. 5 A). Similarly, LRP was detected in detergent extracts of BAE membranes immunoprecipitated with anti-CRT antiserum (Fig. 5 B). LRP was complexed with membrane-associated CRT after hep I treatment, but not in untreated cells or cells treated with the inactive peptide. These data indicate that, in addition to forming bimolecular complexes in vitro, CRT and LRP are associated in cells and hep I treatment enhances CRT-LRP association.

Also, we examined whether hep I and LRP form complexes in cells. Biotin-tagged hep I was added to wild-type or CRT nulls, and proteins associated with the biotin-tagged peptide were isolated by immunoprecipitation with neutravidin-coupled beads. LRP was detected in lysates from wildtype (but not from CRT-null) MEFs (Fig. 6 A). In cells treated with nontagged hep I or another biotin-tagged CRT-binding peptide (GQPMYGQPMY), no LRP was detected in the neutravidin precipitates. On these membranes stripped and reprobed with anti-CRT antibody, CRT migrating as a high mol wt protein was detected in immunoprecipitated material from the wild-type cells treated with biotin-hep I (unpublished data). CRT associated with the control CRT-binding peptide migrated at $60 \mathrm{kD}$ (unpublished data). LRP is specifically associated with the biotinhep I-CRT complex because we failed to detect association of another membrane protein, $\beta_{3}$ integrin, with this complex (Fig. 6 B). The inability to precipitate LRP from CRTnull cells is not due to a lack of LRP in these cells, as there is equivalent staining for LRP in immunoblots of extracts of wild-type and CRT-null MEFs (Fig. 6 C). Hep I-CRTLRP complex formation is not limited to fibroblasts, as these complexes were also detected in BAE cells (unpublished data).

\section{LRP is necessary for ERK and signaling downstream of TSP/hep I binding to CRT}

If LRP is acting as the signaling coreceptor for CRT, then LRP should be necessary for downstream signals induced by TSP/hep I binding to CRT. Hep I activates PI3K and ERK, and the activity of these mediators is required for hep I-stimulated focal adhesion disassembly (Greenwood et al., 1998; Orr et al., 2002). CRT is necessary for PI3K and ERK signaling in response to hep I (Goicoechea et al., 2000; Orr et al., 2002). Therefore, we tested whether cells that either lack or have reduced levels of LRP are capable of activating these downstream effectors of TSP/hep I signaling.

Treatment of cells with $1 \mu \mathrm{M}$ hep I peptide stimulated a significant increase in ERK phosphorylation in wild-type cells (Fig. 7, A and B). In contrast, there was no stimulation of ERK phosphorylation in the homozygous LRP-deficient cell line PEA 13 (Fig. 7 A). The PEA 10 line heterozygous for LRP showed a reduced ability to phosphorylate ERK in response to hep I treatment. Further evidence for the role of LRP in hep I signaling is seen by the ability of RAP to block ERK phosphorylation in response to hep I in wild-type MEF cells (Fig. 7 B).

The function of LRP as a component of the receptor complex-mediating activation of PI3K was also studied. The generation of PtdIns- $\mathrm{P}_{3}$ in response to stimulation with hep I was examined in an in vitro kinase assay. These data show a
Figure 5. LRP and CRT form complexes in BAE cells. (A) BAE cells were treated with DMEM, $1 \mu \mathrm{M}$ hep I, or $1 \mu \mathrm{M}$ modified hep I for $10 \mathrm{~min}$, and $\mathrm{N}$-octylglucopyranoside membrane extracts were immunoprecipitated with mouse antiLRP antibody (5A6) or nonimmune IgG bound to GammaBind G Sepharose beads. Bound complexes were resolved by SDS-PAGE under nonreducing conditions, and CRT was detected by immunoblotting with goat-anti-CRT IgG. (B) BAE cells were incubated with either DMEM, $1 \mu \mathrm{M}$ hep I, or $1 \mu \mathrm{M}$ modified hep I for $10 \mathrm{~min}$, and detergent extracts of membranes were immunoprecipitated with anti-CRT antiserum or nonimmune rabbit serum; bound LRP was detected by immunoblotting with mouse anti-LRP antibody (8G1).
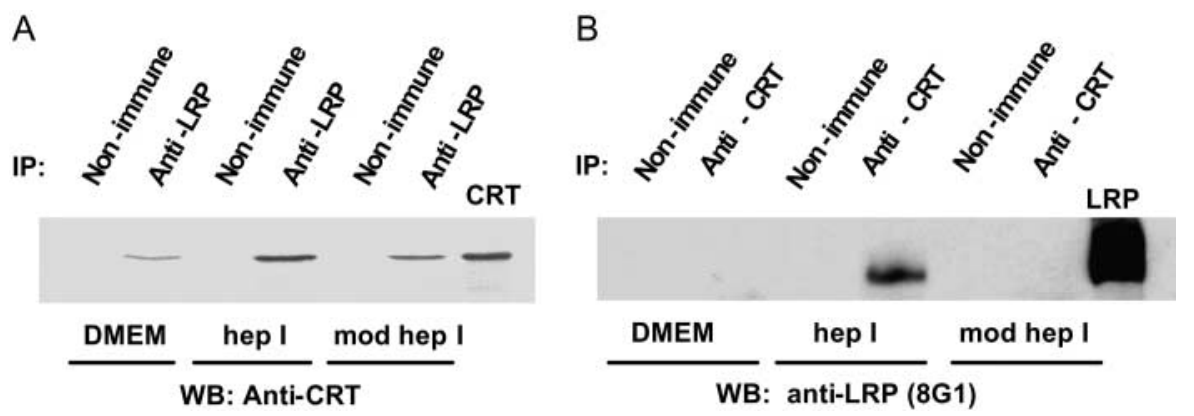
A

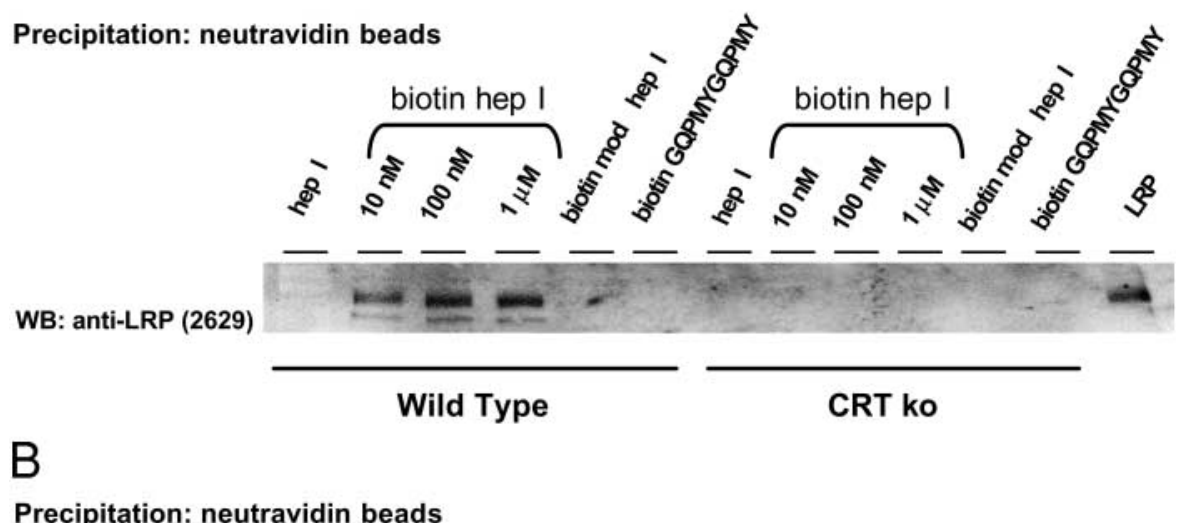

Precipitation: neutravidin beads
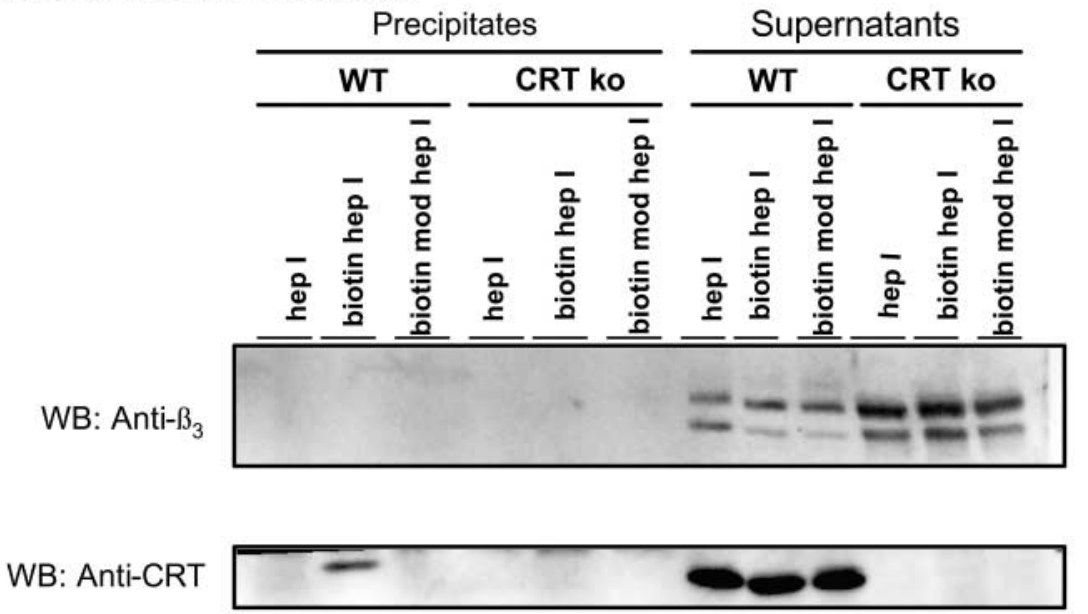

Figure 6. LRP forms molecular complexes with biotin-tagged hep I peptide in wild-type (but not CRT-null) cell extracts. (A) Wild-type and CRT-null MEFs were incubated for $10 \mathrm{~min}$ with $1 \mu \mathrm{M}$ untagged hep I peptide, $10 \mathrm{nM}-1 \mu \mathrm{M}$ biotin-tagged hep I, $1 \mu \mathrm{M}$ biotin-tagged modified hep I, or $1 \mu \mathrm{M}$ biotin-tagged CRT binding peptide. Detergent extracts of cells were coprecipitated with neutravidin beads to precipitate proteins associated with biotin peptides. LRP coprecipitating with the biotin-hep I complexes was detected by immunoblot with rabbit anti-LRP antibody (R2629). LRP was detected in the neutravidinbiotin precipitates from wild-type (but not from CRT-null) MEFs. LRP was not detected in samples treated with nontagged hep I, biotin modified hep I, or the biotin CRT-binding peptide. (B) Wild-type and CRT knockout MEFs were treated with $1 \mu \mathrm{M}$ untagged hep I, biotintagged hep I, or biotin-tagged modified hep I, and associated proteins were precipitated with neutravidin. Precipitated proteins and proteins in the supernatant were assessed by immunoblotting for $\beta_{3}$ integrin and then for CRT in the same membrane. (C) LRP levels were assessed by immunoblot in equivalent amounts of cell protein $(50 \mu \mathrm{g})$ from wild-type and CRT-null MEFs.

C

\section{LRP WT CRT ko}

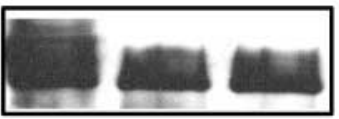

Anti-LRP (2629)

significantly reduced ability to generate PtdIns- $\mathrm{P}_{3}$ in PEA 10 cells that contain low levels of LRP, and a complete inability in the LRP-deficient cell line (Fig. 8; PEA 13). In contrast, hep I stimulated a significant increase in PtdIns- $\mathrm{P}_{3}$ in the wild-type cells containing normal levels of LRP.

\section{Hep I stimulates association of the $G \alpha_{\mathrm{i} 2}$ subunit with LRP}

Hep I/TSP signaling of focal adhesion disassembly through cell surface CRT is PTX-sensitive and involves the $\mathrm{G} \alpha_{\mathrm{i} 2}$ subunit of heterotrimeric G proteins (Orr et al., 2002). Because ligand stimulation can induce association of $\mathrm{G}$ protein subunits with LRP, we asked whether hep I treatment similarly induced $\mathrm{G} \alpha_{\mathrm{i} 2}$ association with LRP in BAE cells. Lysates of hep I-treated cells were immunoprecipitated with antibody to LRP, and the association of the $\mathrm{G} \alpha_{\mathrm{i} 2}$ subunit was assessed by immunoblotting with an antibody specific for this subunit. Data show that hep I induces a time-dependent association of the $\mathrm{G} \alpha_{\mathrm{i} 2}$ subunit with LRP, consistent with the kinetics of hep I-stimulated focal adhesion disassembly (Greenwood et al., 1998; Fig. 9 A). TSP, but not the modi- fied hep I peptide, also stimulates LRP-G $\alpha_{\mathrm{i} 2}$ association (Fig. 9 B). Further evidence that $G$ protein association with LRP is dependent on hep I stimulation is shown by the ability of RAP to block LRP-G protein binding in response to hep I (Fig. 9 C). The association of $\mathrm{G \alpha}_{\mathrm{i} 2}$ with LRP is blocked by a membrane-permeable peptide that inhibits binding of the $\mathrm{G \alpha}_{\mathrm{i} 2}$ subunit to receptors, but not by a related peptide that specifically blocks $\mathrm{G} \alpha_{\mathrm{i} 3}$ binding to receptors (Fig. 9 D). This peptide blocks hep I-dependent focal adhesion disassembly and signaling (Orr et al., 2002). Hep I induces $\mathrm{G} \alpha$ subunit association specifically with LRP because there was no stimulation of $\mathrm{G} \alpha$ association with either the Angiotensin II type 1 receptor or the EGF receptor (Fig. 9 E). These data link LRP to the PTX-sensitive signaling pathway activated by TSP/hep I binding to cell surface CRT.

\section{Discussion}

These analyses identify LRP as the signaling coreceptor for cell surface CRT in mediating TSP-induced focal adhesion 

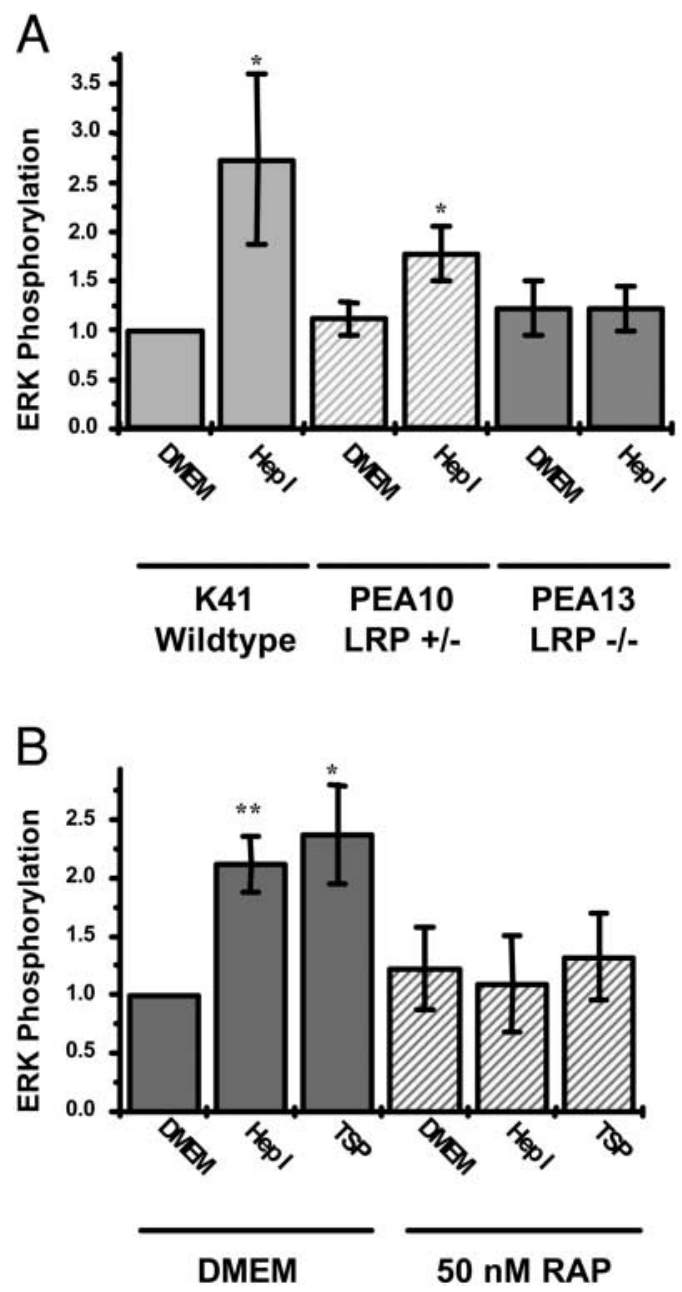

Figure 7. TSP/hep I requires LRP to activate ERK. (A) Wild-type (K41), PEA10 (LRP+/-), and PEA13 (LRP-/-) MEFs were grown to near confluence in 6 -well plates in $1 \%$ FBS overnight. Cells were incubated in serum-free DMEM cells $(4 \mathrm{~h})$ and then treated for 10 min with either $1 \mu \mathrm{M}$ DMEM or $1 \mu \mathrm{M}$ hep I. Cells lysates were analyzed for total and phospho-ERK by immunoblotting. Levels of phospho-ERK were determined through densitometry and normalized to total ERK levels. Results are the mean arbitrary absorbance units \pm $\mathrm{SD}(n=3-4) .{ }^{*}, \mathrm{P}<0.05$ vs. DMEM. (B) K41 MEFs were treated as in A, except that some cultures were treated with $50 \mathrm{nM}$ RAP for the last hour of serum starvation. Cell lysates were probed for phosphoERK and total ERK as in A. Results are the mean arbitrary absorbance units \pm SD $(n=3-4)$. ${ }^{*}, \mathrm{P}<0.05 ;{ }^{* *}, \mathrm{P}<0.01$ vs. DMEM.

disassembly. They provide evidence that LRP binds CRT and that hep I, CRT, and LRP form molecular complexes in cells. Hep I appears to enhance CRT-LRP complex formation. Furthermore, we show that LRP is necessary for focal adhesion disassembly induced by hep I and for generation of the downstream signaling mediators that are required to stimulate reorganization of focal adhesions. There is a critical level of LRP expression that is required to mediate TSPCRT signaling, as cells that express LRP at significantly reduced levels were unable to signal in response to TSP/hep I. LRP appears to be a specific effector of TSP-mediated focal adhesion disassembly because tenascin- $\mathrm{C}$ retained its ability to signal focal adhesion disassembly in LRP-deficient fibroblasts. Finally, we provide evidence linking LRP to the PTX- sensitive $G$ protein subunit involved in hep I signaling of focal adhesion disassembly.

It is becoming clear that beyond its role as a molecular chaperone, CRT also regulates multiple cellular functions as a cell surface protein (Eggleton et al., 1994; Arosa et al., 1999; Johnson et al., 2001; Seddiki et al., 2001). In addition to mediating focal adhesion disassembly in response to TSP, CRT modulates melanoma cell spreading on laminin substrates (White et al., 1995) and fibroblast proliferation in response to fibrinogen (Gray et al., 1995). The mechanisms whereby cell surface CRT mediates cellular signals have not been previously described. Evidence that CRT signaling is PTX-sensitive in at least three different cell types suggests that heterotrimeric $\mathrm{G}$ protein signaling might be a common mechanism (Cho et al., 1999, 2001). Signaling by an antibacterial peptide in U937 monocytes to generate $\mathrm{O}_{2}{ }^{-}$occurs in a $\mathrm{G}$ protein-dependent manner (Cho et al., 2001). Furthermore, cell surface CRT similarly mediates the effects of this anti-microbial peptide on neutrophils through PTXsensitive G proteins (Cho et al., 1999). These findings are consistent with our data showing that TSP stimulates focal adhesion disassembly through activation of PTX-sensitive $\mathrm{G}_{\mathrm{i} 2}$ proteins and ERK phosphorylation (Orr et al., 2002), and with the current data showing that hep I stimulates association of LRP with the $\mathrm{G} \alpha_{\mathrm{i} 2}$ subunit.

Typically, heterotrimeric $\mathrm{G}$ proteins are associated with seven transmembrane-spanning receptors (Gilman, 1987). Although it might be atypical for the $\mathrm{G} \alpha_{\mathrm{i} 2}$ subunit to associate with LRP and mediate signaling, there is precedent for such signaling mechanisms. G proteins are known to associate with single transmembrane types of receptors such as the receptors for insulin, erythropoietin, EGF, and IGF-I and

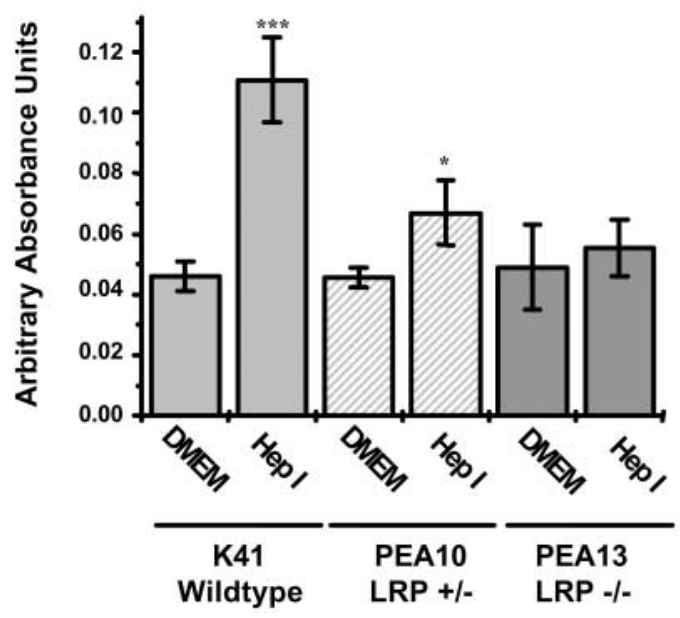

Figure 8. Hep I-mediated PI3K activation requires LRP. Wild-type K 41 MEFs, PEA10, and PEA13 cells were grown to near confluence, serum deprived overnight in $0.2 \% \mathrm{FBS}$, and treated with either 1 $\mu \mathrm{M}$ DMEM or $1 \mu \mathrm{M}$ hep I for $30 \mathrm{~min}$. Cells were lysed and immunoprecipitated with anti-p85 $\mathrm{PI} 3 \mathrm{~K}$ antibodies. Immunoprecipitates then underwent an in vitro lipid kinase assay by successive incubations with phosphatidylinositol-4,5-bisphosphate $\left(\mathrm{PIP}_{2}\right)$ and $\left.{ }^{32} \mathrm{P}\right]$ ATP. Phosphorylated lipids were separated by TLC, detected by autoradiography, and analyzed using densitometry. Results are the mean arbitrary absorbance units $\pm \mathrm{SD}(n=3-5)$. ${ }^{*}, \mathrm{P}<0.05$; ***, $\mathrm{P}<$ 0.001 vs. DMEM. 
A

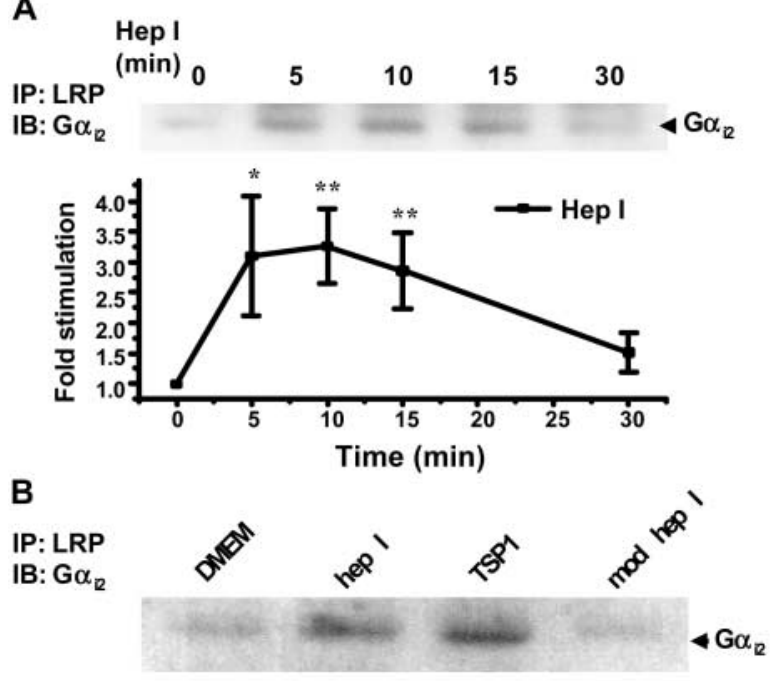

C

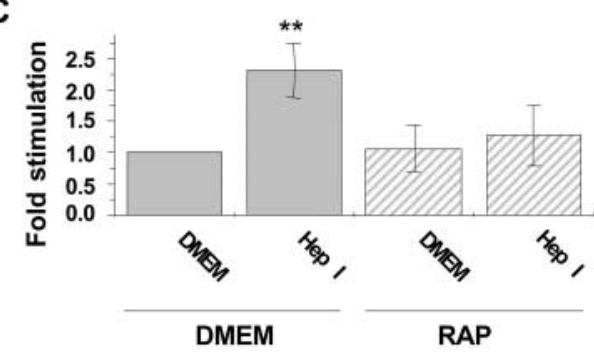

D

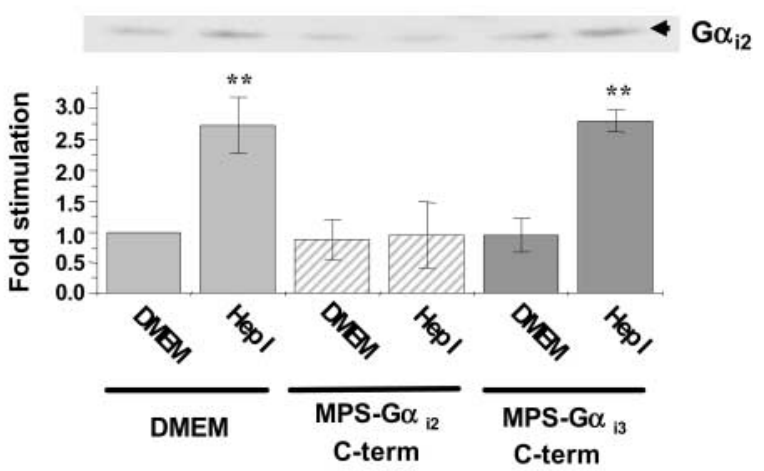

E

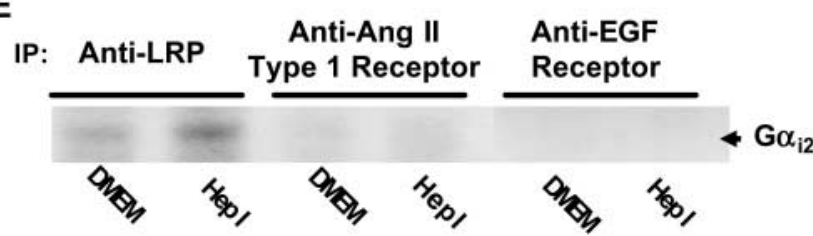

Figure 9. Hep I stimulates association of LRP with the $\mathbf{G} \alpha_{\mathrm{i} 2}$ subunit, and association is blocked by RAP and by peptides corresponding to the $\mathrm{COOH}$ terminus of $\mathrm{G}_{\alpha_{\mathrm{i} 2}}$. (A) BAE cells were grown to near confluence and serum deprived overnight. Cells were then treated with $1 \mu \mathrm{M}$ hep I for $0,5,10,15$, or $30 \mathrm{~min}$ and lysed. Cell lysates were immunoprecipitated with monoclonal anti-LRP antibody (8G1), separated by SDS-PAGE, and immunoblotted with mouse anti-G $\alpha_{\mathrm{i} 2}$ antibodies. A representative immunoblot for LRP-associated $\mathrm{G} \alpha_{\mathrm{i} 2}$ is shown. Bands were analyzed using One-Dscan software (Scanalytics), and the fold change in LRP-G $\alpha_{\mathrm{i} 2}$ association as compared with untreated conditions was determined. Equal loading of sample protein was assessed by protein staining with Ponceau S. *, $\mathrm{P}<0.05$; **, P $<0.01(n=3-5)$. (B) BAE cells were grown as in A, treated for 10 min with either DMEM, $100 \mathrm{nM}$ hep I, $78 \mathrm{nM}$ TSP, or $100 \mathrm{nM}$ modified hep I and assayed for LRP-G $\alpha_{\mathrm{i} 2}$ association as described in A.
IGF-II (Yang et al., 1991; Krieger-Brauer et al., 1997; Fedorov et al., 1998; Hallak et al., 2000; Guillard et al., 2001). LRP has been shown to associate with heterotrimeric $\mathrm{G}$ proteins, primarily $\mathrm{G} \alpha_{s}$, in melanoma cells (Goretzki, and Mueller, 1998). There is also evidence that LRP is involved in G protein signaling; apoE4 binding to LRP stimulates PTX-sensitive neuronal cell apoptosis in association with $\mathrm{G} \alpha_{\mathrm{i}}$ subunits (Hashimoto et al., 2000). ApoE peptides or activating antibodies to LRP stimulate an increase in cytosolic calcium in an LRP- and PTX-sensitive manner (Wang and Gruenstein, 1997; Misra et al., 1999). Our present work provides further evidence for the involvement of LRP in G protein signaling and shows that LRP-G protein interactions are involved in regulation of a defined biological response, focal adhesion disassembly.

Evidence suggests that CRT and LRP interactions are physiologically important. CRT plays a role in $\mathrm{C1q}$ signaling of apoptotic cell ingestion through association with LRP, and the two proteins colocalize on the surface of macrophages (Ogden et al., 2001). Furthermore, CRT and another LRP family member, megalin, both bind C1q (Sim et al., 1998). Other data show that interactions of heat shock proteins gp96, hsp90, and hsp70 with LRP are competitively blocked by CRT, and antibody to LRP blocks antigen presentation by CRT (Basu et al., 2001). Our data are consistent with these observations that CRT-LRP interactions are important in cellular processes and demonstrate a new role for LRP in focal adhesion disassembly.

LRP has signaling functions distinct from its role as a cargo transport protein (Hussain, 2001; for review see Strickland et al., 2002). LRP has two NPxY signaling motifs in its cytoplasmic domain; however, endocytosis depends primarily on a YXXL sequence immediately after the second NPxY motif (NPVYxxL). Both NPxY motifs appear to interact with signaling adaptor molecules (Li et al., 2000). LRP associates with numerous adaptor molecules including Fe65 (Ermekova et al., 1997), Disabled-1 (Dab-1; Trommsdorff et al., 1998, 1999), JIP 1 and 2 (Gotthardt et al., 2000), and Shc (Barnes et al., 2001). A tyrosine-phosphorylated form of LRP copurified with Shc in v-src transformed cells (Barnes et al., 2001). This finding is intriguing, as Shc activates the Ras signaling pathway and downstream ERK activation through recruitment of Grb2-Sos (Nakamura et al., 2002). Recently, we showed that TSP/hep I signaling through CRT stimulates ERK activity, and that ERK activ-

A representative immunoblot for $\mathrm{LRP}$-associated $\mathrm{G} \alpha_{\mathrm{i} 2}$ is shown $(n=3)$. (C) BAE cells were grown as in A and pretreated for $1 \mathrm{~h}$ in DMEM with or without $50 \mathrm{nM}$ RAP and then treated with either DMEM or $1 \mu \mathrm{M}$ hep I for $10 \mathrm{~min}$ and assayed for LRP-G $\alpha_{\mathrm{i} 2}$ association as described in A. ${ }^{* *}, \mathrm{P}<0.01(n=4)$. (D) BAE cells were pretreated for $1 \mathrm{~h}$ in DMEM with or without $1 \mu \mathrm{M}$ membrane-permeable sequence (MPS)-G $\alpha_{\mathrm{i} 2}$ or MPS-G $\alpha_{\mathrm{i} 3}$ peptides. Cells were then treated with either DMEM or $1 \mu \mathrm{M}$ hep I for $10 \mathrm{~min}$ and lysed. Cells were then treated with either DMEM or $1 \mu \mathrm{M}$ hep I for $10 \mathrm{~min}$ and assayed for $\mathrm{LRP}-\mathrm{G} \alpha_{\mathrm{i} 2}$ association as described in A. ${ }^{* *}, \mathrm{P}<0.01(n=3-5)$. (E) BAE cells were treated with either DMEM or $1 \mu \mathrm{M}$ hep I for 10 $\mathrm{min}$ and lysed. Cell lysates were immunoprecipitated with anti-LRP antibody (8G1), anti-angiotensin II type 1 receptor antibody, or anti-EGF receptor antibody, separated by SDS-PAGE, and immunoblotted with mouse anti-G $\alpha_{\mathrm{i} 2}$ antibodies. Results are representative of at least three experiments. 
ity is required for focal adhesion disassembly (Orr et al., 2002). LRP also appears to be involved in PI3K signaling as $\alpha_{2} \mathrm{M}$ binding to LRP on peritoneal macrophages activates PI3K (Misra and Pizzo, 1998). This is consistent with our observations that cells deficient in LRP do not activate PI3K in response to hep I stimulation. Together, these observations support a direct role for LRP in transmitting signals from TSP bound to CRT.

Also, we report here that LRP binds CRT and forms complexes with CRT in cells. TSP/hep I binds aa 19-36 of the N-domain of CRT, and this interaction mediates focal adhesion disassembly (Goicoechea et al., 2002). Our in vitro binding analyses suggest that hep I binding to CRT does not interfere with the ability of LRP to bind CRT (unpublished data). On the contrary, hep I increases CRT-LRP association at the cell membrane. PAI-1 binding to uPAR exposes a cryptic binding site on uPAR for LRP (Stefansson et al., 1998). TSP/hep I binding to CRT might also alter CRT structure, exposing a new or additional LRP binding sites. Hep I potentially induces CRT clustering at the membrane, thereby increasing CRT affinity for LRP. This model is consistent with the fact that CRT binding to cells in the absence of hep I is insufficient to signal focal adhesion disassembly (Goicoechea et al., 2000, 2002), and the present observation that LRP cocomplexes with a higher mol wt form of CRT.

The extracellular binding domains of LRP involved in binding CRT are not known. Interestingly, the ligand-binding clusters of LRP are comprised of cysteine-rich complement-like repeats (Herz and Strickland, 2001). C1q is a known ligand of CRT, and CRT has been referred to as the cC1q receptor (Eggleton et al., 1998). C1q binds to a site spanning the $\mathrm{N}$ and P domains (aa 160-283) of CRT (Stuart et al., 1997; Kovacs et al., 1998). It is interesting to speculate that CRT recognizes these complement-like domains of LRP.

Although the $\mathrm{NH}_{2}$-terminal heparin-binding domain of TSP binds LRP, and LRP mediates the endocytic degradation of TSP1 and 2 (Godyna et al., 1995; Mikhailenko et al., 1997), our analyses failed to demonstrate binding between LRP and the hep I sequence from the $\mathrm{NH}_{2}$-terminal heparin-binding domain of TSP. It remains to be seen as to whether hep I signaling through LRP modulates endocytic degradation of TSP, or whether LRP down-regulates TSPCRT signaling of focal adhesion disassembly through endocytosis of this complex.

In summary, these works identify a novel mechanism of CRT signaling from the cell surface through TSP-stimulated association with LRP. Furthermore, these data link LRP to the $\mathrm{G} \alpha_{\mathrm{i}}$ signaling pathway activated by TSP/hep I and its downstream effectors, PI3K and ERK. Finally, these data implicate LRP in a novel biologic response, modulation of the intermediate cell adhesion.

\section{Materials and methods}

\section{Cells}

BAE cells were cultured in DMEM with $4.5 \mathrm{~g} /$ glucose, $2 \mathrm{mM}$ glutamine, and 10\% FBS (Murphy-Ullrich et al., 1993). MEF-1 (ATCC-CRL-2214), PEA 10 (ATCC-CRL-2215), and PEA 13 (ATCC-CRL-2216) cells were purchased from the American Type Culture Collection and were grown in DMEM with $4.5 \mathrm{~g} / \mathrm{l}$ glucose, $1 \mathrm{mM}$ sodium pyruvate, $1.5 \mathrm{~g} / \mathrm{l}$ sodium bicarbonate, and $10 \%$ FBS (HyClone). Wild-type (K41) and crt-/- null (K42) MEFs were a gift from Dr. M. Michalak (University of Alberta, Alberta, Canada). Growth conditions were the same as described for BAE cells.

\section{Antibodies}

Rabbit anti-CRT antiserum was purchased from Affinity BioReagents, Inc. Goat anti-CRT IgG (calregulin, sc-6468) was purchased from Santa Cruz Biotechnology, Inc. Anti-CD91 rabbit pAb against LRP (used at 1:5001000) was a gift from Dr. R. Binder (University of Connecticut School of Medicine, Farmington, CT; Binder et al., 2000). R2629 rabbit pAb against LRP, developed in the Strickland lab, and mouse anti-LRP 8G1 and 5A6 antibodies (purchased from Maine Biotechnology) have been described previously (Strickland et al., 1990; Kounnas et al., 1992b). Rabbit antiphospho-ERK, rabbit anti-ERK and mouse anti-EGF receptor antibodies were purchased from Cell Signaling Technology. Rabbit anti- $\beta_{3}$ integrin was purchased from CHEMICON International. Mouse antibody to PI3K (p85 subunit) and mouse anti- $\mathrm{G}_{\mathrm{i} \alpha}$ antibody were purchased from Upstate Biotechnology. Mouse anti-G $\alpha_{\mathrm{i} 2}$ antibody was purchased from BIOMOL Research Laboratories, Inc. Mouse antibody to the Ang II type 1 receptor was purchased from Abcam, Ltd.

\section{Proteins}

TSP was purified from human platelets purchased from the American Red Cross as described previously (Murphy-Ullrich and Höök, 1989). LRP was isolated from human placenta as described previously (Ashcom et al., 1990). Recombinant human RAP expressed as a GST fusion protein was purified as described previously (Williams et al., 1992). Recombinant tenascin-C fnIllA-D was a gift from Dr. Harold Erickson (Duke University, Durham, NC; Aukhil et al., 1993). cDNA for GST-CRT was a gift from Dr. M. Michalak. Fusion proteins were expressed in Escherichia coli and purified as described previously (Baksh and Michalak, 1991; Goicoechea et al., 2000). Hep I peptide, biotin-tagged CRT binding peptide (GQPMYGQPMY), and the membrane-permeable $G$ protein inhibitory peptides were synthesized, purified, and analyzed by AnaSpec (Murphy-Ullrich et al., 1993; Jorgensen et al., 2000; Orr et al., 2002). Hep I peptide with an $\mathrm{NH}_{2}$-terminal biotin tag was synthesized at the University at Alabama, Birmingham Peptide Synthesis Core.

\section{LRP-CRT binding assays}

GST-CRT was expressed as described previously (Goicoechea et al., 2000). The GST tag was cleaved using the Restriction Protease Xa cleavage and removal kit (Roche). $20 \mathrm{nM}$ recombinant CRT was incubated with 10 $\mathrm{nM}$ LRP with or without $10 \mathrm{nM}$ RAP for $1 \mathrm{~h}$ at $4^{\circ} \mathrm{C}$ in DTO buffer (DMEM, $0.5 \%$ Tween 20 , and $0.1 \%$ ovalbumin). Complexes were immunoprecipitated $\left(1 \mathrm{~h}\right.$ at $\left.4^{\circ} \mathrm{C}\right)$ with anti-CRT anti-serum $(1: 30)$ or $15 \mu \mathrm{g} / \mathrm{ml}$ nonimmune rabbit IgG conjugated to GammaBind G Sepharose (Amersham Biosciences). As a control for nonspecific binding, LRP was incubated with 20 $\mathrm{nM} B S A$ in the presence or absence of RAP, and then subjected to immunoprecipitation with rabbit anti-BSA serum (1:30; Sigma-Aldrich) conjugated to GammaBind G Sepharose. Complexes were washed $7 \times$ in DTO buffer and resuspended in Laemmli buffer. Samples were separated by SDS-PAGE $(6 \%)$, transferred to nitrocellulose, and then probed with antiLRP antibody (8G1) at $1 \mu \mathrm{g} / \mathrm{ml}$ and goat anti-mouse IgG-HRP $(1: 10,000)$. Blots were developed using Western Lightning Chemluminescence Reagent Plus (PerkinElmer). Band intensity was quantified by densitometry (One-DScan software v1.31; Scanalytics).

\section{Coprecipitation of LRP and CRT from cell extracts}

BAE cells $(4 \times 100 \mathrm{mM})$ were grown to near confluence, washed three times in DMEM, and cells were then treated with $1 \mu \mathrm{M}$ hep I or the modified hep I peptide for $10 \mathrm{~min}$ before harvesting by scraping. Cells were pelleted, and pellets were washed twice with DMEM plus protease inhibitors. Cells were disrupted by homogenization with a tissue grinder (20 strokes) on ice, and insoluble proteins were pelleted before detergent extraction. The pellet was resuspended in $0.5 \mathrm{ml} 100 \mathrm{mM} \mathrm{N}$-octylglucopyranoside on ice for 40-60 min. Insoluble proteins were removed by centrifugation, and equal amounts of protein from the detergent-soluble supernatant (extract) were used for the coimmunoprecipitation assays.

GammaBind G Sepharose beads were blocked overnight in blocking buffer $(0.1 \%$ ovalbumin in DMEM), and were then incubated for $1-2 \mathrm{~h}$ with $15 \mu \mathrm{l}$ rabbit anti-CRT antiserum or nonimmune rabbit serum. Beads were washed four times and were then incubated for $1 \mathrm{~h}$ at $4^{\circ} \mathrm{C}$ with 360 $\mu \mathrm{g}$ of BAE cell extract in an equal volume of $2 \times$ binding buffer $(0.1 \%$ Triton $\mathrm{X}-100$ in DMEM). Beads were washed four times with binding buffer and immune complexes were extracted in $30 \mu \mathrm{l} 2 \times$ nonreducing Laemmli buffer. LRP was detected in anti-CRT immunoprecipitated complexes by 
immunoblotting with mouse anti-LRP antibody (8G1) at $1 \mu \mathrm{g} / \mathrm{ml}$. Alternately, CRT was detected in samples immunoprecipitated with $5 \mu \mathrm{g}$ mouse anti-LRP (5A6) antibody or nonimmune mouse serum by immunoblotting with goat anti-CRT IgG $(1: 1,000)$.

\section{Association of LRP with biotin-tagged hep I peptide bound to cells}

Wild-type and CRT-null MEFs were incubated with biotin-tagged hep I peptide, untagged peptide for $10 \mathrm{~min}$, washed in DMEM, and cells were then harvested by scraping. Membrane proteins were solubilized with 50 $\mathrm{mM} \mathrm{N}$-octylglucopyranoside. Equal amounts of protein $(1 \mathrm{mg})$ from each cell type were analyzed. Proteins associated with biotinylated hep I were coprecipitated by incubation overnight at $4^{\circ} \mathrm{C}$ with a $100-\mu /$ slurry of neutravidin beads (Pierce Chemical Co.). Samples were washed seven times in DTO buffer. Bound proteins were solubilized in Laemmli buffer and separated by SDS-PAGE on $6 \%$ gels. After transfer to nitrocellulose, LRP coprecipitating with the biotin peptide complexes was detected by immunoblotting with $1 \mu \mathrm{g} / \mathrm{ml}$ rabbit anti-LRP antibody (R2629). In replicate experiments, membranes were probed with rabbit antibody to $\beta_{3}$ integrin and then stripped and reprobed with chicken anti-CRT. Equal amounts (50 $\mu \mathrm{g})$ of detergent extract from the wild-type and CRT-null MEFS were probed for LRP by immunoblotting with rabbit anti-LRP antibody (R2629). In some experiments, replicate blots were probed with anti-CRT antiserum to confirm peptide binding. A biotin-tagged peptide known to bind CRT (GQPMYGQPMY; Jorgensen et al., 2000), but which does not stimulate focal adhesion disassembly was also tested.

\section{Focal adhesion assay}

The focal adhesion assays were performed as described previously (Murphy-Ullrich and Höök, 1989). Cells were preincubated under serum-free conditions for $30 \mathrm{~min}$ before treatment for $30 \mathrm{~min}$ at $37^{\circ} \mathrm{C}$ with hep I or TSP. Endogenous TSP production during the course of these assays is not a factor because mouse fibroblasts derived from TSP1 and TSP2 double knockout animals respond to TSP1 and hep I as do wild-type cells (fibroblasts were a gift of Dr. Paul Bornstein, University of Washington, Seattle, WA.

\section{ERK activation assay}

ERK activity was determined by Western blotting using phosphorylation state-specific antibodies of whole-cell lysates as described previously (Orr et al., 2002).

\section{Immunoprecipitation and PI3K assay}

Phosphatidylinositol $(4,5)$-bisphosphate $\left(\mathrm{PIP}_{2}\right)$ was obtained from American Radiolabeled Chemicals, and ${ }^{32}$ P]ATP was purchased from Amersham Biosciences. PI3K activity was assessed in an in vitro kinase assay in anti-p85 immunoprecipitates using a $\mathrm{PIP}_{2}$ substrate as described previously (Greenwood et al., 1998)

\section{G protein pull-down assay}

BAE cells were grown to near confluence, serum-deprived, and incubated with either DMEM or hep I, modified hep I, or TSP. Cells were lysed and immunoprecipitated with mouse anti-LRP (8G1) antibody for $2 \mathrm{~h}$ at $4^{\circ} \mathrm{C}$ as described previously (Orr et al., 2002). In some experiments, lysates were immunoprecipitated with antibodies to either the angiotensin II type 1 receptor or to the EGF receptor. As an additional control, cells were preincubated for $1 \mathrm{~h}$ with $50 \mathrm{nM}$ RAP before addition of hep I. Immunoprecipitates were analyzed for $\mathrm{G} \alpha_{\mathrm{i} 2}$ association by immunoblotting with mouse anti-G $\alpha_{\mathrm{i} 2}$ antibodies followed by HRP-conjugated goat anti-mouse IgG $(1: 5,000)$. Bands were visualized with chemiluminescence reagent (NEN Life Science Products).

The authors gratefully acknowledge Dr. Marek Michalak for the wild-type MEFs and the CRT constructs, and Dr. R. Binder for providing the CD91 anti-LRP antibody.

This work was supported by National Institutes of Health grants HL44575 to J.E. Murphy-Ullrich, and HL50784 and HL54710 to D.K. Strickland; by the Cardiovascular Pathology training grant (T 32 HL07918) to A.W. Orr; by the Bone Biology and Disease training grant (T32 AR47512) to C.A. Elzie; and by the American Heart Association, Southeastern Affiliate, post-doctoral fellowships to C.E. Pedraza (0120251B) and to S. Goicoechea (0020534B).

Submitted: 12 February 2003

Revised: 7 May 2003

Accepted: 9 May 2003

\section{References}

Arosa, F.A., O. de Jesus, G. Porto, A.M. Carmo, and M. de Sousa. 1999. Calreticulin is expressed on the cell surface of activated human peripheral blood T lymphocytes in association with major histocompatibility complex class I molecules. J. Biol. Chem. 274:16917-16922.

Ashcom, J.D., S.E. Tiller, K. Dickerson, J.L. Cravens, W.S. Argraves, and D.K. Strickland. 1990. The human alpha 2-macroglobulin receptor: identification of a $420-\mathrm{kD}$ cell surface glycoprotein specific for the activated conformation of alpha 2-macroglobulin. J. Cell Biol. 110:1041-1048.

Aukhil, I., P. Joshi, Y. Yan, and H.P. Erickson. 1993. Cell- and heparin-binding domains of the hexabrachion arm identified by tenascin expression proteins. J. Biol. Chem. 268:2542-2553.

Baksh, S., and M. Michalak. 1991. Expression of calreticulin in Escherichia coli and identification of its $\mathrm{Ca}^{2+}$ binding domains. J. Biol. Chem. 266:2145821465.

Barnes, H., B. Larsen, M. Tyers, and P. van Der Geer. 2001. Tyrosine-phosphorylated low density lipoprotein receptor-related protein 1 (LRP1) associates with the adapter protein SHC in SRC-transformed cells. J. Biol. Chem. 276: 19119-19125.

Basu, S., R.J. Binder, T. Ramalingam, and P.K. Srivastava. 2001. CD91 is a common receptor for heat shock proteins gp96, hsp90, hsp70, and calreticulin. Immunity. 14:303-313.

Binder, R.J., D.K. Han, and P.K. Srivastava. 2000. CD91: a receptor for heat shock protein gp96. Nat. Immunol. 1:151-155.

Boucher, P., P. Liu, M. Gotthardt, T. Hiesberger, R.G. Anderson, and J. Herz. 2002. Platelet-derived growth factor mediates tyrosine phosphorylation of the cytoplasmic domain of the low density lipoprotein receptor-related protein in caveolae. J. Biol. Chem. 277:15507-15513.

Burridge, K., and M. Chrzanowska-Wodnicka. 1996. Focal adhesions, contractility, and signaling. Annu. Rev. Cell Dev. Biol. 12:463-518

Cho, J.H., K. Homma, S. Kanegasaki, and S. Natori. 1999. Activation of human neutrophils by a synthetic anti-microbial peptide, KLKLLLLLKLK-NH2, via cell surface calreticulin. Eur. J. Biochem. 266:878-885.

Cho, J.H., K.J. Homma, S. Kanegasaki, and S. Natori. 2001. Activation of human monocyte cell line U937 via cell surface calreticulin. Cell Stress Chaperones. 6:148-152.

Eggleton, P., T.S. Lieu, E.G. Zappi, K. Sastry, J. Coburn, K.S. Zaner, R.D. Sontheimer, J.D. Capra, B. Ghebrehiwet, and A.I. Tauber. 1994. Calreticulin is released from activated neutrophils and binds to $\mathrm{C} 1 \mathrm{q}$ and mannanbinding protein. Clin. Immunol. Immunopathol. 72:405-409.

Eggleton, P., K.B. Reid, and A.J. Tenner. 1998. C1q-how many functions? How many receptors? Trends Cell Biol. 8:428-431.

Ermekova, K.S., N. Zambrano, H. Linn, G. Minopoli, F. Gertler, T. Russo, and M. Sudol. 1997. The WW domain of neural protein FE65 interacts with proline-rich motifs in Mena, the mammalian homolog of Drosophila enabled. J. Biol. Chem. 272:32869-32877.

Fedorov, Y.V., N.C. Jones, and B.B. Olwin. 1998. Regulation of myogenesis by fibroblast growth factors requires beta-gamma subunits of pertussis toxin-sensitive G proteins. Mol. Cell. Biol. 18:5780-5787.

Gilman, A.G. 1987. G proteins: transducers of receptor-generated signals. Annu. Rev. Biochem. 56:615-649.

Gliemann, J., A. Nykjaer, C.M. Petersen, K.E. Jorgensen, M. Nielsen, P.A. Andreasen, E.I. Christensen, A. Lookene, G. Olivecrona, and S.K. Moestrup. 1994. The multiligand alpha 2-macroglobulin receptor/low density lipoprotein receptor-related protein (alpha 2MR/LRP). Binding and endocytosis of fluid phase and membrane-associated ligands. Ann. NY Acad. Sci. 737:20-38.

Godyna, S., G. Liau, I. Popa, S. Stefansson, and W.S. Argraves. 1995. Identification of the low density lipoprotein receptor-related protein (LRP) as an endocytic receptor for thrombospondin-1. J. Cell Biol. 129:1403-1410.

Goicoechea, S., A.W. Orr, M.A. Pallero, P. Eggleton, and J.E. Murphy-Ullrich. 2000. Thrombospondin mediates focal adhesion disassembly through interactions with cell surface calreticulin. J. Biol. Chem. 275:36358-36368.

Goicoechea, S., M.A. Pallero, P. Eggleton, M. Michalak, and J.E. Murphy-Ullrich. 2002. The anti-adhesive activity of thrombospondin is mediated by the N-terminal domain of cell surface calreticulin. J. Biol. Chem. 277:3721937228.

Goretzki, L., and B.M. Mueller. 1998. Low-density-lipoprotein-receptor-related protein (LRP) interacts with a GTP-binding protein. Biochem. J. 336:381386.

Gotthardt, M., M. Trommsdorff, M.F. Nevitt, J. Shelton, J.A. Richardson, W. Stockinger, J. Nimpf, and J. Herz. 2000. Interactions of the low density li- 
poprotein receptor gene family with cytosolic adaptor and scaffold proteins suggest diverse biological functions in cellular communication and signal transduction. J. Biol. Chem. 275:25616-25624.

Gray, A.J., P.W. Park, T.J. Broekelmann, G.J. Laurent, J.T. Reeves, K.R. Stenmark, and R.P. Mecham. 1995. The mitogenic effects of the B beta chain of fibrinogen are mediated through cell surface calreticulin. J. Biol. Chem. 270: 26602-26606.

Greenwood, J.A., M.A. Pallero, A.B. Theibert, and J.E. Murphy-Ullrich. 1998. Thrombospondin signaling of focal adhesion disassembly requires activation of phosphoinositide 3-kinase. J. Biol. Chem. 273:1755-1763.

Guillard, C., S. Chretien, R. Jockers, S. Fichelson, P. Mayeux, and V. Duprez. 2001. Coupling of heterotrimeric $G_{i}$ proteins to the erythropoietin receptor. J. Biol. Chem. 276:2007-2014.

Hallak, H., A.E. Seiler, J.S. Green, B.N. Ross, and R. Rubin. 2000. Association of heterotrimeric $\mathrm{G}_{\mathrm{i}}$ with the insulin-like growth factor-I receptor. Release of Gß $\gamma$ subunits upon receptor activation. J. Biol. Chem. 275:2255-2258.

Hashimoto, Y., H. Jiang, T. Niikura, Y. Ito, A. Hagiwara, K. Umezawa, Y. Abe, Y. Murayama, and I. Nishimoto. 2000. Neuronal apoptosis by apolipoprotein E4 through low-density lipoprotein receptor-related protein and heterotrimeric GTPases. J. Neurosci. 20:8401-8409.

Herz, J., and D.K. Strickland. 2001. LRP: a multifunctional scavenger and signaling receptor. J. Clin. Invest. 108:779-784.

Herz, J., R.C. Kowal, J.L. Goldstein, and M.S. Brown. 1990. Proteolytic processing of the $600 \mathrm{kd}$ low density lipoprotein receptor-related protein (LRP) occurs in a trans-Golgi compartment. EMBO J. 9:1769-1776.

Horwitz, A.R., and Z. Werb. 1998. Cell-to-cell contact and extracellular matrix cell adhesion and the extracellular matrix: recent progress and emerging themes. Curr. Opin. Cell Biol. 10:563-565.

Hussain, M.M. 2001. Structural, biochemical and signaling properties of the lowdensity lipoprotein receptor gene family. Front. Biosci. 6:D417-D428.

Johnson, S., M. Michalak, M. Opas, and P. Eggleton. 2001. The ins and outs of calreticulin: from the ER lumen to the extracellular space. Trends Cell Biol. 11:122-129.

Jorgensen, C.S., N.H.H. Heegaard, A. Holm, P. Hojrup, and G. Houen. 2000. Polypeptide binding properties of the chaperone calreticulin. Eur. J. Biochem. 267:2945-2954.

Kounnas, M.Z., W.S. Argraves, and D.K. Strickland. 1992a. The 39-kDa receptor-associated protein interacts with two members of the low density lipoprotein receptor family, alpha 2-macroglobulin receptor and glycoprotein. 330. J. Biol. Chem. 267:21162-21166.

Kounnas, M.Z., R.E. Morris, M.R. Thompson, D.J. FitzGerald, D.K. Strickland, and C.B. Saelinger. 1992b. The alpha 2-macroglobulin receptor/low density lipoprotein receptor-related protein binds and internalizes Pseudomonas exotoxin A. J. Biol. Chem. 267:12420-12423.

Kovacs, H., I.D. Campbell, P. Strong, S. Johnson, F.J. Ward, K.B. Reid, and P. Eggleton. 1998. Evidence that $\mathrm{C} 1 \mathrm{q}$ binds specifically to $\mathrm{CH} 2$-like immunoglobulin gamma motifs present in the autoantigen calreticulin and interferes with complement activation. Biochemistry. 37:17865-17874.

Krieger-Brauer, H.I., P.K. Medda, and H. Kather. 1997. Insulin-induced activation of NADPH-dependent $\mathrm{H}_{2} \mathrm{O}_{2}$ generation in human adipocyte plasma membranes is mediated by G $\alpha_{\mathrm{i} 2}$. J. Biol. Chem. 272:10135-10143.

Li, Y., M.P. Marzolo, P. van Kerkhof, G.J. Strous, and G. Bu. 2000. The YXXL motif, but not the two NPXY motifs, serves as the dominant endocytosis signal for low density lipoprotein receptor-related protein. J. Biol. Chem. 275: $17187-17194$

Loukinova, E., S. Ranganathan, S. Kuznetsov, N. Gorlatova, M.M. Migliorini, D. Loukinov, P.G. Ulery, I. Mikhailenko, D.A. Lawrence, and D.K. Strickland. 2002. Platelet-derived growth factor (PDGF)-induced tyrosine phosphorylation of the low density lipoprotein receptor-related protein (LRP). Evidence for integrated co-receptor function between LRP and the PDGF. J. Biol. Chem. 277:15499-15506.

Lutz, C., J. Nimpf, M. Jenny, K. Boecklinger, C. Enzinger, G. Utermann, G. Baier-Bitterlich, and G. Baier. 2002. Evidence of functional modulation of the MEKK/JNK/cJun signaling cascade by the low density lipoprotein receptor-related protein (LRP). J. Biol. Chem. 277:43143-43151.

Medh, J.D., G.L. Fry, S.L. Bowen, M.W. Pladet, D.K. Strickland, and D.A. Chappell. 1995. The 39-kDa receptor-associated protein modulates lipoprotein catabolism by binding to LDL receptors. J. Biol. Chem. 270:536-540.

Mikhailenko, I., D. Krylov, K.M. Argraves, D.D. Roberts, G. Liau, and D.K. Strickland. 1997. Cellular internalization and degradation of thrombospondin-1 is mediated by the amino-terminal heparin binding domain (HBD). High affinity interaction of dimeric HBD with the low density lipoprotein receptor-related protein. J. Biol. Chem. 272:6784-6791.

Misra, U.K., and S.V. Pizzo. 1998. Binding of receptor-recognized forms of alpha2-macroglobulin to the alpha2-macroglobulin signaling receptor activates phosphatidylinositol 3-kinase. J. Biol. Chem. 273:13399-13402.

Misra, U.K., G. Gawdi, and S.V. Pizzo. 1999. Ligation of low-density lipoprotein receptor-related retain with antibodies elevates intracellular calcium and inositiol 1,45-trisphosphate in macrophages. Arch. Biochem. Biophys. 372:238247.

Murphy-Ullrich, J.E. 2001. The de-adhesive activity of matricellular proteins: is intermediate cell adhesion an adaptive state? J. Clin. Invest. 107:785-790.

Murphy-Ullrich, J.E., and M. Höök. 1989. Thrombospondin modulates focal adhesions in endothelial cells. J. Cell Biol. 109:1309-1319.

Murphy-Ullrich, J.E., V.A. Lightner, I. Aukhil, Y.Z. Yan, H.P. Erickson, and M. Höök. 1991. Focal adhesion integrity is down regulated by the alternatively spliced domain of human tenascin. J. Cell Biol. 115:1127-1136.

Murphy-Ullrich, J.E., S. Gurusiddappa, W.A. Frazier, and M. Höök. 1993. Heparin-binding peptides from thrombospondins 1 and 2 contain focal adhesion-labilizing activity. J. Biol. Chem. 268:26784-26789.

Nakamura, T., M. Komiya, N. Gotoh, S. Koizumi, M. Shibuya, and N. Mori. 2002. Discrimination between phosphotyrosine-mediated signaling properties of conventional and neuronal Shc adapter molecules. Oncogene. 21:2231 .

Ogden, C.A., A. deCathelineau, P.R. Hoffmann, D. Bratton, B. Ghebrehiwet, V.A. Fadok, and P.M. Henson. 2001. C1q and mannose binding lectin engagement of cell surface calreticulin and CD91 initiates macropinocytosis and uptake of apoptotic cells. J. Exp. Med. 194:781-795.

Orr, A.W., M.A. Pallero, and J.E. Murphy-Ullrich. 2002. Thrombospondin stimulates focal adhesion disassembly through Gi- and phosphoinositide 3-kinase-dependent activation. J. Biol. Chem. 277:20453-20460.

Seddiki, N., F. Nato, P. Lafaye, Z. Amoura, J.C. Piette, and J.C. Mazie. 2001. Calreticulin, a potential cell surface receptor involved in cell penetration of antiDNA antibodies. J. Immunol. 166:6423-6429.

Sim, R.B., S.K. Moestrup, G.R. Stuart, N.J. Lynch, J. Lu, W.J. Schwaeble, and R. Malhotra. 1998. Interaction of $\mathrm{Clq}$ and the collectins with the potential receptors calreticulin (cC1qR/collectin receptor) and megalin. Immunobiology. 199:208-224.

Stefansson, S., S. Muhammad, X.F. Cheng, F.D. Battey, D.K. Strickland, and D.A. Lawrence. 1998. Plasminogen activator inhibitor-1 contains a cryptic high affinity binding site for the low density lipoprotein receptor-related protein. J. Biol. Chem. 273:6358-6366.

Strickland, D., S. Gonias, and W. Argraves. 2002. Diverse roles for LDL receptor family. Trends Endocrinol. Metab. 13:66-74.

Strickland, D.K., J.D. Ashcom, S. Williams, W.H. Burgess, M. Migliorini, and W.S. Argraves. 1990. Sequence identity between the alpha 2-macroglobulin receptor and low density lipoprotein receptor-related protein suggests that this molecule is a multifunctional receptor. J. Biol. Chem. 265:1740117404 .

Strickland, D.K., J.D. Ashcom, S. Williams, F. Battey, E. Behre, K. McTigue, J.F. Battey, and W.S. Argraves. 1991. Primary structure of alpha 2-macroglobulin receptor-associated protein. Human homologue of a Heymann nephritis antigen. J. Biol. Chem. 266:13364-13369.

Stuart, G.R., N.J. Lynch, A.J. Day, W.J. Schwaeble, and R.B. Sim. 1997. The C1q and collectin binding site within $\mathrm{Clq}$ receptor (cell surface calreticulin). Immunopharmacology. 38:73-80.

Tamai, K., M. Semenov, Y. Kato, R. Spokony, C. Liu, Y. Katsuyama, F. Hess, J.P. Saint-Jeannet, and X. He. 2000. LDL-receptor-related proteins in Wnt signal transduction. Nature. 407:530-535.

Trommsdorff, M., J.P. Borg, B. Margolis, and J. Herz. 1998. Interaction of cytosolic adaptor proteins with neuronal apolipoprotein $\mathrm{E}$ receptors and the amyloid precursor protein. J. Biol. Chem. 273:33556-33560.

Trommsdorff, M., M. Gotthardt, T. Hiesberger, J. Shelton, W. Stockinger, J. Nimpf, R.E. Hammer, J.A. Richardson, and J. Herz. 1999. Reeler/Disabledlike disruption of neuronal migration in knockout mice lacking the VLDL receptor and ApoE receptor 2. Cell. 97:689-701.

Wang, X.S., and E. Gruenstein. 1997. Rapid elevation of neuronal cytoplasmic calcium by apolipoprotein E peptide. J. Cell. Physiol. 173:73-83.

Wehrli, M., S.T. Dougan, K. Caldwell, L. O'Keefe, S. Schwartz, D. VaizelOhayon, E. Schejter, A. Tomlinson, and S. DiNardo. 2000. Arrow encodes an LDL-receptor-related protein essential for Wingless signalling. Nature. 407:527-530.

White, T.K., Q. Zhu, and M.L. Tanzer. 1995. Cell surface calreticulin is a putative mannoside lectin which triggers mouse melanoma cell spreading. J. Biol. 
Chem. 270:15926-15929

Williams, S.E., J.D. Ashcom, W.S. Argraves, and D.K. Strickland. 1992. A novel mechanism for controlling the activity of alpha 2-macroglobulin receptor/ low density lipoprotein receptor-related protein. Multiple regulatory sites for 39-kDa receptor-associated protein. J. Biol. Chem. 267:9035-9040.

Willnow, T.E., and J. Herz. 1994. Genetic deficiency in low density lipoprotein receptor-related protein confers cellular resistance to Pseudomonas exotoxin A. Evidence that this protein is required for uptake and degradation of multiple ligands. J. Cell Sci. 107:719-726.
Willnow, T.E., J.M. Moehring, N.M. Inocencio, T.J. Moehring, and J. Herz. 1996. The low-density-lipoprotein receptor-related protein (LRP) is processed by furin in vivo and in vitro. Biochem. J. 313:71-76.

Yamada, K.M., and B. Geiger. 1997. Molecular interactions in cell adhesion complexes. Curr. Opin. Cell Biol. 9:76-85.

Yang, L.J., G. Baffy, S.G. Rhee, D. Manning, C.A. Hansen, and J.R. Williamson. 1991. Pertussis toxin-sensitive $G_{i}$ protein involvement in epidermal growth factor-induced activation of phospholipase C-gamma in rat hepatocytes. $J$. Biol. Chem. 266:22451-22458. 